\title{
Minimum quantity lubrication: Quantifying non-deterministic component of sustainability index for machining operations
}

\author{
M.S. Najiha1, M.M. Rahman² and K. Kadirgama ${ }^{2}$ \\ ${ }^{1}$ International Affairs and training Division \\ Pakistan Atomic Energy Commission, Karachi, Pakistan \\ ${ }^{2}$ Faculty of Mechanical Engineering, Universiti Malaysia Pahang, \\ 26600 Pekan, Pahang, Malaysia. \\ Email: mustafizur@ump.edu.my \\ Phone: +6094246239; +6094246222
}

\begin{abstract}
Sustainable manufacturing is pursued to achieve the long-term sustainable development of manufacturing systems. In practice, the sustainability of any system is difficult to assess because of uncertain factors involved in the sustainability study. Experts have defined a sustainability index in order to define any system. This sustainability index consists of two components, namely the deterministic component and non-deterministic component. The nondeterministic component consists of the contributing factors of societal, environmental, and economic effects. On account of the uncertainties involved and the non-quantifiable nature of the non-deterministic component, fuzzy logic is used to assess the non-deterministic component. In this paper the nondeterministic component of the sustainability index for a machining process with Minimal Quantity Lubrication is calculated using fuzzy logic. The basic objective of this study is to quantify the non-deterministic component of the sustainability index by using a fuzzy rule-based model for the anticipation and functional analysis of machining with minimal quantity lubrication.
\end{abstract}

Keywords: Sustainable manufacturing; sustainability index; manufacturing; fuzzy logic; minimum quantity lubrication.

\section{INTRODUCTION}

Sustainable development is a broad term that emerged during environmental discussions and movements during the 1970s. It provides a balance between the three Ps, i.e. profit, people, and the planet. The most generally acknowledged description of sustainable development is given by the 1987 Brundtland Commission Report for the UN [1]: "Sustainable Development is meeting the needs of present without compromising the ability of future generations to meet their own needs." Sustainable development has three components, namely societal sustainability, environmental sustainability, and economic sustainability [2-4]. The recent surge in thrive towards sustainable systems and development is accelerating due to the challenges facing the planet from a large number of directions - from scientific societies to consumers. Sustainable development in a global context includes essential elements in all the disciplines as well as machining processes. Sustainable manufacturing is a subset of broader sustainable development. The best definition of sustainable manufacturing is given by the U.S. Department of Commerce 
(DOC) [5]: "The creation of manufactured products that use processes that minimise negative environmental impacts, conserve energy and natural resources, are safe for employees, communities, and consumers and are economically sound." The continuous surge towards sustainability has concluded that cost-effective mass manufacturing is not adequate to thrive but implementing sustainable manufacturing practices is very important. Sustainable manufacturing techniques when applied may result in improved energy utilisation, waste administration, ecological effects, process and personnel safety, and human health. In order to implement sustainability principles in manufacturing, both the product and process design and innovations must aim at accomplishing the three components of sustainable development, i.e. societal, environmental, and, of course, economical. However, modelling, implementing and optimising sustainability in manufacturing is not an easy task as manifold intricate trade-offs are involved in product designs and process planning. Implementing sustainability values in manufacturing practices results in a cost-effective means of developing economically, environmentally and socially viable systems (i.e. the three foundations of sustainability). Adopting sustainable manufacturing practices leads to adopting the six basic pillars of sustainability, namely

i). reduced manufacturing costs, using lean manufacturing and best machining practices,

ii). reduced and efficient resource consumption,

iii). minimised waste management, i.e. less waste - reduced generation and increased recycling of waste,

iv). improved environmental impact - good working conditions,

v). enhanced operational safety training of employees about sustainable machining practices, and

vi). improved personnel health and safety performance. Figure 1.

The six basic elements of sustainable manufacturing can best be presented as in

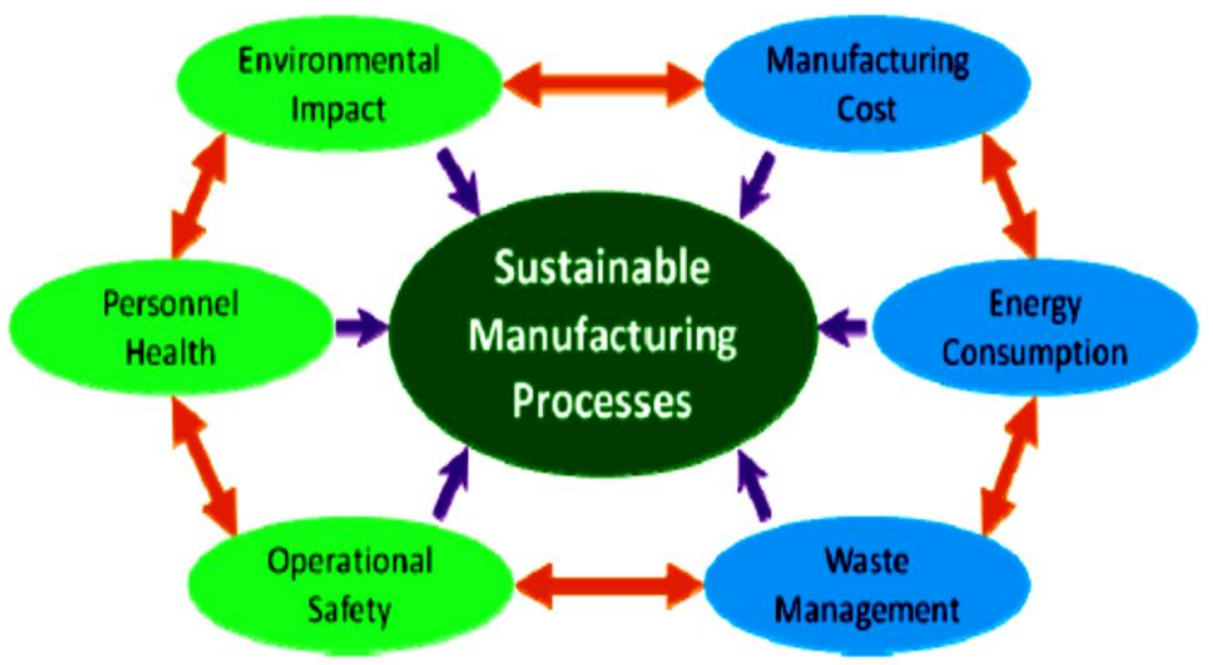

Figure 1. Six basic factors contributing to sustainable manufacturing processes [6]. 
Keeping in view all the elements of sustainable manufacturing, the machining industry keeps on finding methods and techniques for increased machining process performance with cost-effectiveness. Global ecological consciousness, which has pressured the industry to reduce production cost, has directed the industry to give careful thought to the role of conventional metalworking fluids used in machining processes. Minimum quantity lubrication (MQL) is a new sustainable practice of cooling and lubrication in machining that has resulted in the optimised use of metalworking fluids. The goal of MQL is to produce parts using an optimised minimum quantity of metalworking fluids so that the work piece, chips and environment remain dry after cutting. MQL has proved to be an effective near-dry machining technique from the viewpoint of cost and ecological and human health issues. According to research the cost of using metalworking fluids may range from $7 \%$ to $17 \%$ of the total cost of the manufactured workpiece [7]. This cost is very significant, thus by applying the MQL technique a notable reduction in machining costs can be realised just by optimising the quantity of lubricant used in machining. MQL is a sustainable manufacturing technique that is harmless for the eco-sphere and the machinist and that is cost-effective [8]. The minimisation of metalworking fluids is a gauge of sustainable manufacturing. MQL has been proven to provide several advantages, such as the chips, work piece and tool holder having low cooling and lubricating fluids leftovers, and therefore their clean-up and material recycling is easier and inexpensive; the work place is also not contaminated, thus assisting monitoring of the cutting operation at the floor. MQL is an achievement-oriented technology, which replaces conventional lubrication techniques and takes over the lubrication task, and assisting sustainable development, in mechanical manufacturing processes.

The manufacturing practices and technologies adopted as a part of sustainable machining have been evaluated, analysed and optimised for sustainability impacts. Even though sustainable machining is a critical aspect of sustainable manufacturing, the studies carried out to assess the ecological and social effects of sustainable machining are insufficient. Most of the current research which analyses the effects of sustainability is limited to economic aspects, i.e. discovering newer techniques of material removal as a substitute for conventional machining or optimisation of the various variables contributing to the machining process. Some of the research has attempted to analyse environmental impacts $[9,10]$. In a study carried out by Rotella et al. [11], the milling process of a non-conventional material, $\gamma$-TiAl alloy, is analysed for ecological and environmental effects with three cooling and lubricating conditions, i.e. flooded cooling, MQL, and dry machining. Shao et al. [12] proposed a methodology that uses a virtual model of a machining system to analyse the environmental impact of the process. The objective of the simulation system, scope, model elements, and their input and output requirements are discussed. This approach allows the assessment of environmental impact in a virtual environment using real world data, specification data, and simulation data as input and the provision of a platform to evaluate different options for optimal decisionmaking. A lot of research has been conducted in the field of MQL as a sustainable manufacturing technique [13-16]. This is because of the fact that metalworking fluids used as cooling and lubricating media in machining operations create many concerns related to personnel health and safety as well as a significant increase in the cost of machining operations. However, most available data is limited to the effects of MQL on machining parameters such as surface roughness, tool wear, etc. Very few studies have been done on the estimation of the sustainability indicators or indices for MQL. Some of the research has attempted to evaluate the sustainability indices for conventional 
machining operations. Granados et al. [17] present a new methodology involving the use of fuzzy logic and analytical models for sustainability assessment in manufacturing, in particular machining. In this case, the most sustainable cutting conditions for conventional roughing and finishing in a turning operation have been determined.

In the subject study, the fuzzy logic technique is applied to MQL for a generalised machining operation in order to predict the non-deterministic component of a sustainability index using MATLAB software's Fuzzy Logic Toolbox. The nondeterministic component of the hybrid model developed by Granados et al. [17], which was formulated for a comprehensive sustainability evaluation of machining processes, is evaluated irrespective of any particular machining process. Three different levels are defined for different factors contributing towards environmental friendliness, operator safety and process safety. These different factors are then evaluated using the Fuzzy Logic Toolbox to calculate environmental friendliness, operator safety and process safety of the machining, which are then used to determine the contribution of the non-deterministic sustainability elements towards the sustainability index. Certain assumptions are made to accommodate the management decisions in the modelling of the parameters. For the assessment of the non-deterministic component of the sustainability index, different parameters are defined and classified as factors split into three levels; these factors are then ascertained and arranged as linguistic variables, and then interrelated through fuzzy rules. Finally, the defuzzification is done to find out the crisp outputs in the form of numerical values.

\section{MANUFACTURING PROCESS SUSTAINABILITY EVALUATION}

Sustainable manufacturing is integral to a sustainable society with balanced environmental performance aiming at economic objectives. The six basic elements of sustainability are interrelated and, on account of their complex interactions, the best level of each of these cannot be achieved without any trade-offs. Due to their significant contributions a model to evaluate process sustainability is needed. Wanigarathne et al. [18] developed a sustainability assessment methodology for machining processes, which has subsequently been extended to include a quantitative model for the complete evaluation of machining process sustainability for optimised machining operations with the help of a hybrid model [19]. These six elements of sustainable manufacturing are so interrelated that modelling and integrating these factors into one hybrid model is very challenging. All six factors cannot be uniquely defined and quantification of some of the factors is very difficult. Three out of the six factors (namely manufacturing costs, resource consumption and waste management) are quantifiable in nature and are thus called deterministic terms, while the other three components (namely environmental effects, operator safety and process safety) are non-quantifiable and are thus non-deterministic in nature. The deterministic terms can be determined using analytical and numerical methods depending on the machining data, while the non-deterministic elements can be modelled using non-deterministic means such as the fuzzy logic technique [17]. The nondeterministic component is evaluated using fuzzy logic and optimised by management decisions and the fulfilment of manufacturing norms and regulations [17]. Granados and Jawahir et al. [17] have developed a comprehensive hybrid model for the sustainability evaluation of machining processes by broadening the scope of the sustainability evaluation analysis method for the machining processes adopted by Wanigarathne et al. [18]. A sustainability index is also embedded in this model as an optimisation module in order to estimate the optimum sustainability of the subject machining process. Hence, 
the overall sustainability value determined from the analysis for a machining process would be considered as a collective function of the deterministic and non-deterministic sustainability factors which is expressed as Eq.(1) [20].

$$
S=C_{S H E} \cdot S_{S H E}+C_{O P} \cdot S_{O P}
$$

where $\mathrm{S}$ is the overall sustainability index, $\mathrm{S}_{\mathrm{SHE}}$ is the non-deterministic component of the sustainability index for process and personnel health and safety along with environment, determined using non-deterministic methods such as $\mathrm{S}_{\mathrm{OP}}$, which is the operational or deterministic component of the sustainability index as a function of the machining cost, electrical power consumption and waste management; $\mathrm{C}_{\mathrm{SHE}}, \mathrm{C}_{\mathrm{OP}}$ are weighting factors for non-deterministic and deterministic components, respectively.

The use of fuzzy set theory for the determination of the non-deterministic component of the sustainability index is quite reasonable. Granados and Jawahir et al. (2009) [17] have used the Fuzzy Logic Toolbox for the same purpose. According to their research the use of fuzzy logic to determine the sustainability level of safety, health and environmental issues involved in machining processes is well-justified because fuzzy logic deals with parameters which are not easy to understand $[17,18]$. The fuzzy logic approach seems very suitable for dealing with uncertain phenomena or perception-based information. Fuzzy logic is a theoretically simple and comprehendible method and even applies to systems which are based on opinions and perceptions. The mathematical theory behind fuzzy analysis is very simple. A common sense approach renders it preferable to the other techniques. In the area of human subjectivity, fuzzy logic performs successfully [21-23]. An important benefit of fuzzy logic is that it applies rules with linguistic variables. It takes into account those factors which are difficult to quantify, such as values or opinions [17].

In a fuzzy logic-based system expert comprehension and opinions are expressed as logical rules made with linguistic variables for a complete description of all the possible fuzzy functions between input variables and crisp outputs. If there is no data, intuition, inductive reasoning or experience can be tools for setting the rules. In each rule a set of predecessor schemes is given in which attribute names and attribute values are assigned to each variable and the variables may be defined as very poor or poor, very high or low, or yes or no depending on the variable nature, etc. The linguistic variables attributed to the inputs are inexact without exception considering the non-quantifiable nature of the data which is usually opinion-based and insufficient resulting in imprecise statements. The deduction of a fuzzy system is a three-tier process:

i). Fuzzification of inputs: all the crisp quantities are converted to fuzzy values whereby the imprecisions and uncertainties are represented by membership functions.

ii). Application of fuzzy operator: Boolean operators are applied and expert knowledge is used in the form of fuzzy rules. Rules are made to link the linguistic non-numeric inputs to numeric outputs. A logical IF-THEN rule is used with a situation and a termination. These fuzzy rules consist of an antecedent proposition (between the IF and THEN) and a consequent proposition (following THEN). The antecedent block consists of input linguistic variables that may be combined using Boolean operators. The consequent part contains the output of the fuzzy rule.

iii). Apply the aggregation method: After fuzzification and the evaluation of rules, the fuzzy output from each of the rules is obtained. In order to find out an 
aggregate single fuzzy output result these individual fuzzy outputs are to be combined. A Mamdani inference system gives the maximum of each rule's outputs as the rule base output. Weightage is assigned to the rules on the basis of their significance. The maximum weightage is one, and the minimum weightage is zero. The fuzzy output of each rule is then multiplied by its weight.

After the composition and aggregation, the next stage is the defuzzification process to get a numeric output from the aggregated fuzzy output.

\section{METHODOLOGY}

In this paper three different levels of factors are defined to completely describe the nondeterministic component of the sustainability index. The level 3 factors interact with each other and thus contribute to the level 2 factors. The level 2 factors then interrelate to each other to give level 1 factors. The output from level 1 is then the function of all the factors from all the levels, which are calculated using fuzzy logic. All the inputs are related to each other through fuzzy statements. The IF-THEN rule is applied to relate the inputs based on the previous literature, expert opinions and workshop information. Granados et al. [17] have defined five linguistic levels depending on the nature of the base variable and by following the same criterion. In this paper the same criteria is applied to machining with MQL in order to assess the sustainability of the process. The factors contributing to the final score are defined in three different levels, as shown in Table 1.

Table 1. Factors contributing towards the sustainability index are divided into three levels

\begin{tabular}{lll}
\hline \multicolumn{1}{c}{ Level 1 } & \multicolumn{1}{c}{ Level 2 } & \multicolumn{1}{c}{ Level 3 } \\
\hline Environmental & Safety of Operator & Mist Generation \\
Friendliness (\%) & Safety of Process & Coolant losses \\
& Chip Recycling Rate \\
Process safety (\%) & Waste Generation & Coolant on work piece and chips \\
& Work Place Contamination & Toxic \& Dangerous Additives \\
Operator safety (\%) & Level of Recycling & $\begin{array}{l}\text { Protection } \\
\text { Equipment Malfunction }\end{array}$ \\
& & Operator Training \\
\hline
\end{tabular}

\section{Assumptions}

The following assumptions are made in this study:

1. Chip recycling rate is $80 \%$.

2. Coolant recycling rate is $0 \%$.

3. Coolant loss through splashes is $0 \%$.

4. Coolant loss through leaks is $10 \%$.

5. Mist Generation is $50 \%$ of the allowable $0.5 \mathrm{mg} / \mathrm{m}^{3}$.

6. Operator protection includes all the necessary clothing, masks and shields.

7. As we are using MQL, waste generation is taken as $0 \%$.

8. For MQL, coolant on the chips and workpiece is negligible. In the study a maximum $2 \%$ coolant is assumed so that the chips are assumed dry. 


\section{Linguistic Variables}

The linguistic variables for all of the three level factors are assigned the linguistic values of very low (VL), low (L), normal $(\mathrm{N})$, high $(\mathrm{H})$ and very high $(\mathrm{H})$. Trapezoidal membership functions are used for the variables. Mamdani-type fuzzy inference system is selected for the modelling study. The Area Centroid Method is used for defuzzification. The Centroid, (CoA/CoG) method determines the geometric gravity centre of the shape of the fuzzy output set. The mathematical expression of the CoG method for continuous membership function is given in Eq.(2) and the geometric illustration of the CoG defuzzification method is given in Figure 2. The three levels and the contributing factors used in this study are shown in Figure 3. Figure 4 shows schematic diagram of the fuzzy inference system.

$$
y^{*}=\frac{\int U \cdot y \cdot \mu_{U} \cdot(y) \cdot d y}{\int U \cdot \mu_{U} \cdot(y) \cdot d y}
$$

where $y^{*}$ is the output variable of one set of input variables.

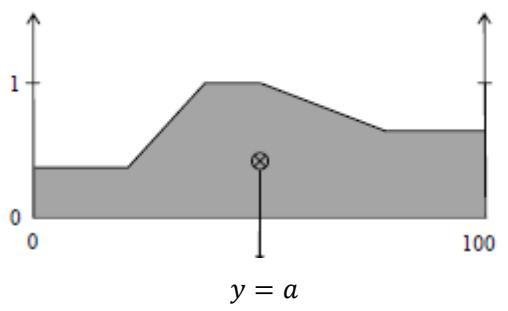

Figure 2. Application of CoG defuzzification method to the fuzzy output result.

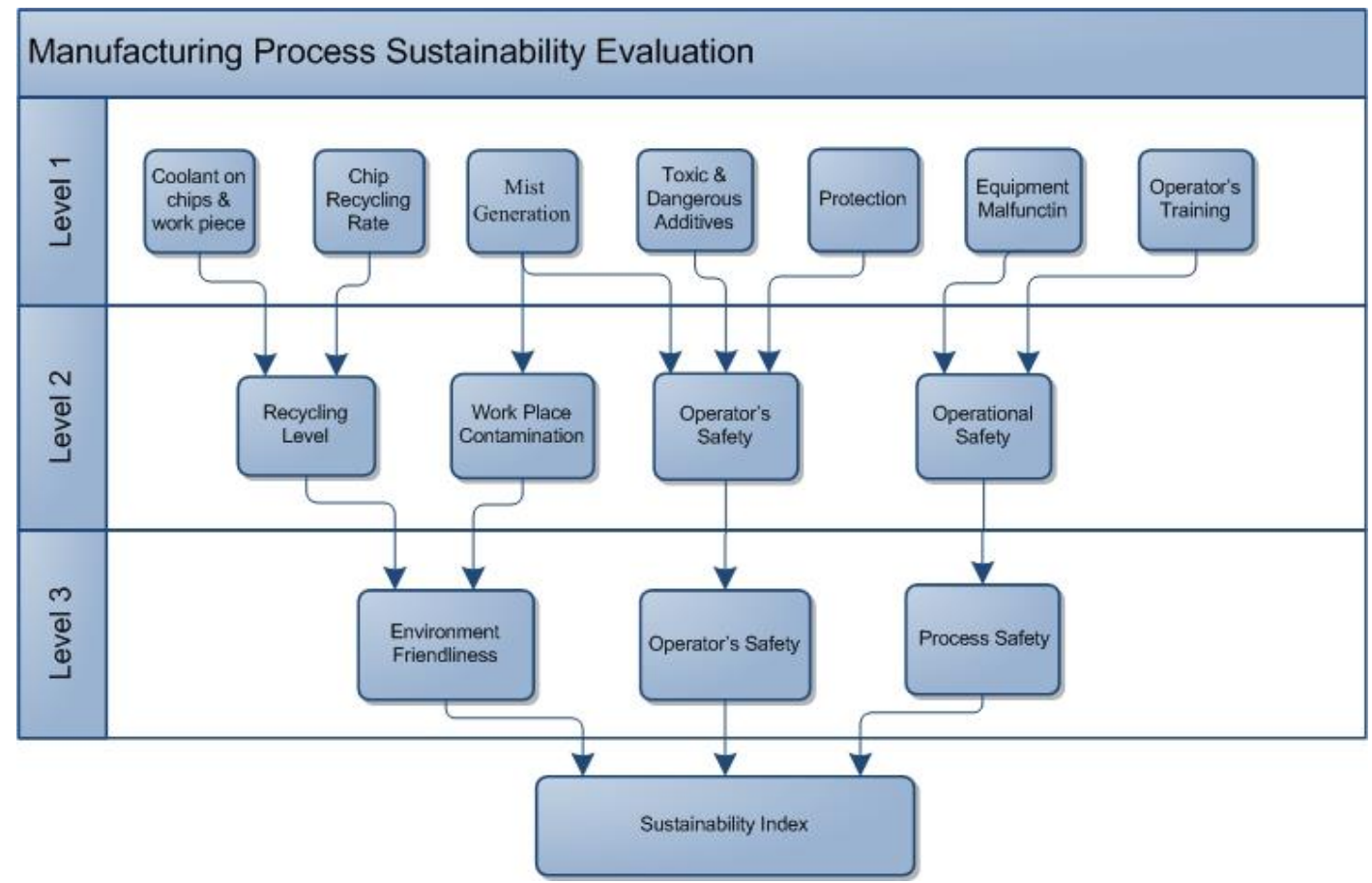

Figure 3. Flowchart for the methodology used 


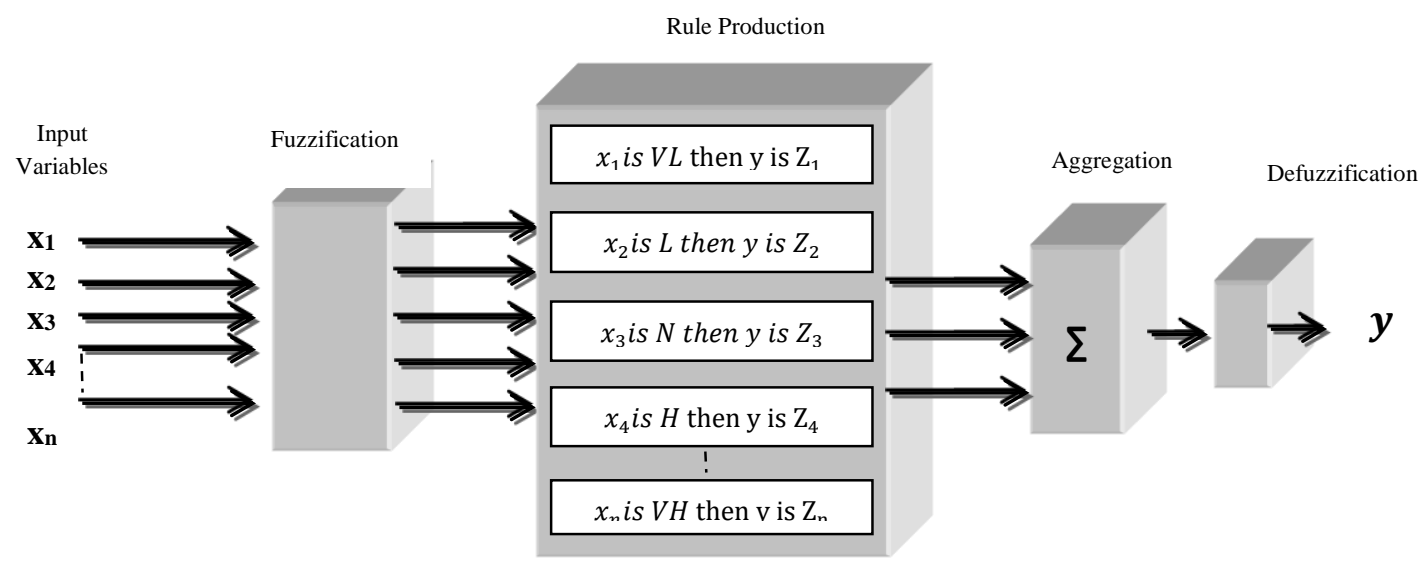

Figure 4. Schematic diagram of the fuzzy inference system.

Figure 5 shows how the fuzzy inference system is applied to the level 2 factor Operator Safety. The rule production rule shows how the level 1 factor Operator Protection (OP) contributes to Operator Safety (OS).

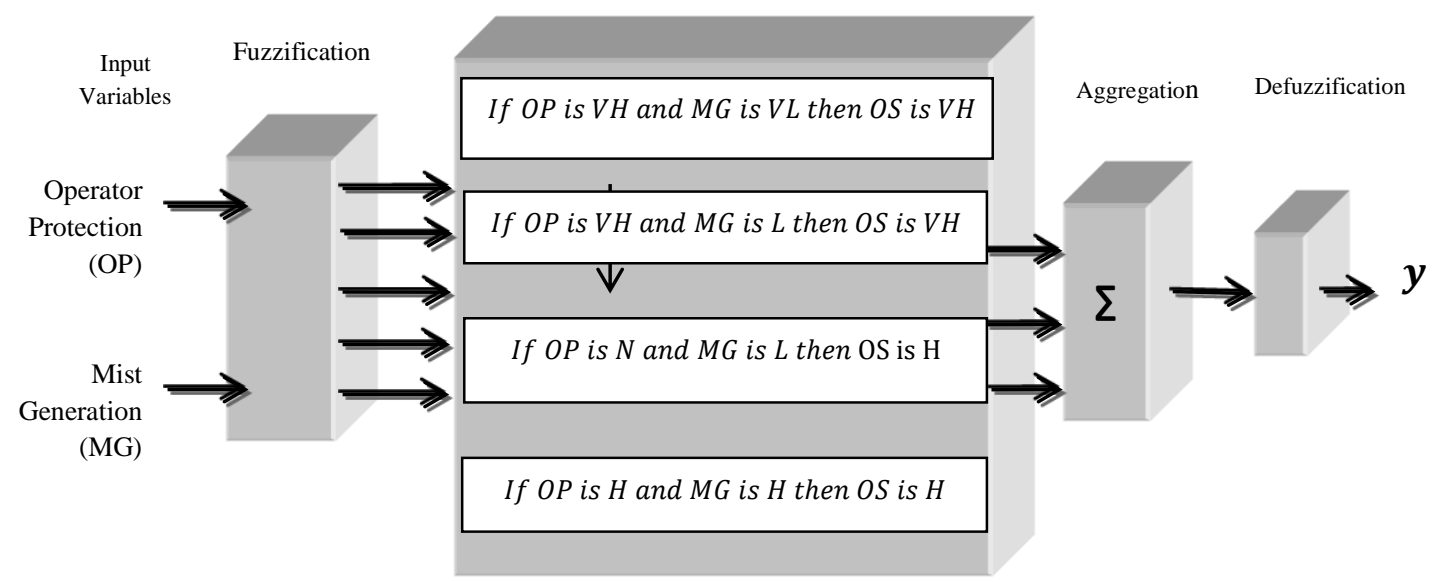

Figure 5. Fuzzy logic applied to operator protection, mist generation and operator safety.

\section{RESULTS AND DISCUSSION}

In the present study the non-deterministic component of the sustainability index is predicted and analysed for machining with the MQL technique. This component is influenced by three primary inputs, namely environmental friendliness, process safety, and operator safety. A three-level fuzzy logic-based model is constructed, where uncertainties are expressed as fuzzy numbers and intervals. Fuzzy rules are developed according to the interrelationship of different factors. These rules are structured to assess each of the specific types of sustainability, e.g. operational, environmental, and personnel safety, using the selected sustainability indicators. The outputs from the aggregation of these rules and subsequent defuzzification are used to evaluate the non-deterministic component of manufacturing sustainability. Each set of input data is entered to the fuzzy inference system and output results are obtained. By applying the fuzzy sustainability 
assessment method, the values of the selected sustainability indicators for the existing system are determined. The crisp output values obtained by including each input dataset (indicators for sustainability) in the testing group are presented in Table 2.

Table 2. Outputs (Sustainability Indicators)

\begin{tabular}{cc}
\hline Output & Sustainability Indicators (\%) \\
\hline Environmental Friendliness (\%) & 79 \\
Operator Safety (\%) & 50 \\
Operational Safety (\%) & 63.6 \\
\hline $\boldsymbol{S}_{\text {SHE }}$ & $\mathbf{6 4 . 2}$ \\
\hline
\end{tabular}

The non-deterministic component of sustainability index (see Eq.(1)) comes out as $64.2 \%$. A three level fuzzy-logic base inference system is employed to find out the nondeterministic component of the sustainability index in a machining process with the MQL technique. The three levels include all the factors that contribute to the sustainability of a machining process. Most of the values and ranges attributed to the factors are based on previous literature. Fuzzy rules are developed according to the interactions of different factors. Fuzzy rules are formulated for classifying different factors as very low, low, normal, high and very high and these rules are applied in order to aggregate the output of each rule. The antecedent blocks are associated with each other using an AND operator, resulting in some consequences. As a result of modelling, non-deterministic components as well as three main contributing factors are calculated. Linguistic variables and weightage are attributed to different factors on the basis of engineering judgment, e.g. training is assigned a weightage of $70 \%$ while equipment malfunction is assigned a value of $30 \%$. Furthermore, mist generation, toxic and dangerous additives and protection are attributed $100 \%$ weightage. In the calculations for operator safety, full (100\%) weightage is given to all the input variables so as to be on the conservative side with respect to operator safety. It is assumed that chips are dry in a near-dry machining process (machining with MQL), so a very small value (2\%) is assigned to the coolant on the chips and workpiece factor.

Granados et al. [19] have calculated the non-deterministic component of a conventional turning operation. The calculated value from their study is $61.5 \%$, while in subject study the result is $64.2 \%$ for MQL study. There is not an appreciable difference between the two results. The reduction in our probability is due to the assumption of parameters on a very conservative side. For example, the referred study has assumed the chip recycling rate as $100 \%$ in conventional machining, while in the subject study the chip recycling rate is assumed as $80 \%$. Furthermore, in the subject study two additional variables are included, namely operator training and equipment malfunctioning. In our case, it is seen that environmental friendliness contributed more towards the sustainability index while operator safety contributed less. In the calculations for operator safety, full $(100 \%)$ weightage is given to all the input variables so as to be on the conservative side with respect to operator safety. On the basis of the crisp outputs, given our inputs and attributes, it is seen that machining with MQL is quite sustainable with respect to environmental safety, operator safety and process safety. Better appreciation of the nondeterministic component of the sustainability index can be modelled using shop-floor data. 


\section{CONCLUSIONS}

The sustainability assessment of any manufacturing system can be divided into two parts; a deterministic assessment and a non-deterministic assessment. The most challenging part of the sustainability assessment is to conduct the non-deterministic assessment. The estimation of the non-deterministic component of the sustainability index thus performed can be used as a part of overall sustainability. It can be used to assess manufacturing systems with data and information uncertainty to determine their sustainability status. However, in the absence of experimental evidence, the prediction capabilities of these models cannot be verified. Therefore in order to analyse and compare the prediction capabilities of these models, their results must be compared with experimental values.

\section{REFERENCES}

[1] Drexhage J, Murphy D. Sustainable development: from Brundtland to Rio 2012. Background paper prepared for consideration by the High Level Panel on Global Sustainability at its first meeting 19 September 2010. 2010.

[2] Najiha MS, Rahman MM, Yusoff AR. Environmental impacts and hazards associated with metal working fluids and recent advances in the sustainable systems: A review. Renewable and Sustainable Energy Reviews. 2016;60:100831.

[3] Najiha MS, Rahman MM, Kadirgama K. Performance of water-based TiO2 nanofluid during the minimum quantity lubrication machining of aluminium alloy, AA6061-T6. Journal of Cleaner Production. 2016.

[4] Najiha MS, Rahman MM, Yusoff AR. Flank wear characterization in aluminum alloy (6061 T6) with nanofluid minimum quantity lubrication environment using an uncoated carbide tool. Journal of Manufacturing Science and Engineering, Transactions of ASME. 2015; 137(6), 061004, 1-7.

[5] Trade U. sustainbility manufacturing. USA Goverment: USA Goverment; 2016.

[6] Jawahir I, Dillon O. Sustainable manufacturing processes: new challenges for developing predictive models and optimization techniques. Proceedings of the First International Conference on Sustainable Manufacturing, Montreal, Canada. 2007; 1-19.

[7] Weinert K, Inasaki I, Sutherland J, Wakabayashi T. Dry machining and minimum quantity lubrication. CIRP Annals-Manufacturing Technology. 2004;53:511-37.

[8] Marksberry P, Jawahir I. A comprehensive tool-wear/tool-life performance model in the evaluation of NDM (near dry machining) for sustainable manufacturing. International Journal of Machine Tools and Manufacture. 2008;48:878-86.

[9] Najiha MS, Rahman MM, Kadirgama K. Machining performance of aluminum alloy 6061-T6 on surface finish using minimum quantity lubrication. International Journal of Automotive and Mechanical Engineering. 2015;11:2699-712.

[10] Najiha MS, Rahman MM, Yusoff AR, Kadirgama K. Investigation of flow behavior in minimum quantity lubrication nozzle for end milling processes. International Journal of Automotive and Mechanical Engineering. 2012;6:768-76.

[11] Rotella G, Priarone PC, Rizzuti S, Settineri L. Evaluation of the environmental impact of different lubrorefrigeration conditions in milling of $\gamma$-TiAl alloy. Glocalized Solutions for Sustainability in Manufacturing: Springer; 2011. p. 36570. 
[12] Shao G, Kibira D, Lyons K. A virtual machining model for sustainability analysis. ASME 2010 International Design Engineering Technical Conferences and Computers and Information in Engineering Conference: American Society of Mechanical Engineers; 2010. p. 875-83.

[13] Najiha MS, Rahman MM, Kadirgama K. Machining performance of aluminum alloy 6061-t6 on surface finish using minimum quantity lubrication. International Journal of Automotive and Mechanical Engineering. 2015;11:2699-712.

[14] Najiha MS, Rahman MM. Experimental study on minimum quantity lubrication in end milling of AA6061-T6 using tialn coated carbide tools. International Journal of Automotive and Mechanical Engineering. 2015;11:2771-85.

[15] Puvanesan M, Rahman MM, Najiha MS, Kadirgama K. Experimental investigation of minimum quantity lubrication on tool wear in aluminum alloy 6061-T6 using different cutting tools. International Journal of Automotive and Mechanical Engineering. 2014;9:1538-49.

[16] Najiha MS, Rahman MM, Yusoff AR, Kadirgama K. Investigation of flow behavior in minimum quantity lubrication nozzle for end milling processes. International Journal of Automotive and Mechanical Engineering. 2012;6:768-76.

[17] Granados S, Jawahir I, Fernandez J. A comprehensive criterion for sustainability evaluation of machining processes. Proceedings of the 7th Global Conference on Sustainable Manufacturing, Chennai, India. 2009; 385-91.

[18] Wanigarathne P, Liew J, Wang X, Dillon Jr O, Jawahir I. Assessment of process sustainability for product manufacture in machining operations. Proceedings of the Global Conference on Sustainable Product Development and Life Cycle Engineering, Berlin, Germany. 2004;305-12.

[19] Granados S, Fernandez J, Jawahir IS. A comprehensive criterion for sustainability assessment and optimization in multi-pass turning operations. International Journal of Production Research. 2007.

[20] Jayal A, Badurdeen F, Dillon O, Jawahir I. Sustainable manufacturing: Modeling and optimization challenges at the product, process and system levels. CIRP Journal of Manufacturing Science and Technology. 2010;2:144-52.

[21] Zadeh LA. Outline of a new approach to the analysis of complex systems and decision processes. IEEE Transactions on Systems, Man, and Cybernetics. 1973:28-44.

[22] Zadeh LA. A theory of approximate reasoning. Machine Intelligence. 1979;9:14994.

[23] Zimmermann H-J. Fuzzy control. fuzzy set theory-and its applications: Springer; 1996; 203-40. 